NASA/TM-2005-213373

\title{
Intelligent Life-Extending Controls for Aircraft Engines
}

Ten-Huei Guo

Glenn Research Center, Cleveland, Ohio

Philip Chen

University of Texas at San Antonio, San Antonio, Texas

Link Jaw

Scientific Monitoring, Inc., Scottsdale, Arizona 
Since its founding, NASA has been dedicated to the advancement of aeronautics and space science. The NASA Scientific and Technical Information (STI) Program Office plays a key part in helping NASA maintain this important role.

The NASA STI Program Office is operated by Langley Research Center, the Lead Center for NASA's scientific and technical information. The NASA STI Program Office provides access to the NASA STI Database, the largest collection of aeronautical and space science STI in the world. The Program Office is also NASA's institutional mechanism for disseminating the results of its research and development activities. These results are published by NASA in the NASA STI Report Series, which includes the following report types:

- TECHNICAL PUBLICATION. Reports of completed research or a major significant phase of research that present the results of NASA programs and include extensive data or theoretical analysis. Includes compilations of significant scientific and technical data and information deemed to be of continuing reference value. NASA's counterpart of peerreviewed formal professional papers but has less stringent limitations on manuscript length and extent of graphic presentations.

- TECHNICAL MEMORANDUM. Scientific and technical findings that are preliminary or of specialized interest, e.g., quick release reports, working papers, and bibliographies that contain minimal annotation. Does not contain extensive analysis.

- CONTRACTOR REPORT. Scientific and technical findings by NASA-sponsored contractors and grantees.
- CONFERENCE PUBLICATION. Collected papers from scientific and technical conferences, symposia, seminars, or other meetings sponsored or cosponsored by NASA.

- SPECIAL PUBLICATION. Scientific, technical, or historical information from NASA programs, projects, and missions, often concerned with subjects having substantial public interest.

- TECHNICAL TRANSLATION. Englishlanguage translations of foreign scientific and technical material pertinent to NASA's mission.

Specialized services that complement the STI Program Office's diverse offerings include creating custom thesauri, building customized databases, organizing and publishing research results ... even providing videos.

For more information about the NASA STI Program Office, see the following:

- Access the NASA STI Program Home Page at http://www.sti.nasa.gov

- E-mail your question via the Internet to help@sti.nasa.gov

- Fax your question to the NASA Access Help Desk at 301-621-0134

- Telephone the NASA Access Help Desk at 301-621-0390

- Write to:

NASA Access Help Desk

NASA Center for AeroSpace Information 7121 Standard Drive

Hanover, MD 21076 
NASA/TM-2005-213373

\section{Intelligent Life-Extending Controls for Aircraft Engines}

Ten-Huei Guo

Glenn Research Center, Cleveland, Ohio

Philip Chen

University of Texas at San Antonio, San Antonio, Texas

Link Jaw

Scientific Monitoring, Inc., Scottsdale, Arizona

Prepared for the

First Intelligent Systems Technical Conference

sponsored by the American Institute of Aeronautics and Astronautics Chicago, Illinois, September 20-22, 2004

National Aeronautics and

Space Administration

Glenn Research Center 
Trade names or manufacturers' names are used in this report for identification only. This usage does not constitute an official endorsement, either expressed or implied, by the National Aeronautics and Space Administration.

Available from

NASA Center for Aerospace Information 7121 Standard Drive

Hanover, MD 21076
National Technical Information Service 5285 Port Royal Road Springfield, VA 22100

Available electronically at http:/ /gltrs.grc.nasa.gov 


\title{
Intelligent Life-Extending Controls for Aircraft Engines
}

\author{
Ten-Huei Guo \\ National Aeronautics and Space Administration \\ Glenn Research Center \\ Cleveland, Ohio 44135 \\ Philip Chen \\ University of Texas at San Antonio \\ San Antonio, Texas 78249 \\ Link Jaw \\ Scientific Monitoring, Inc. \\ Scottsdale, Arizona 85258
}

\begin{abstract}
Aircraft engine controllers are designed and operated to provide desired performance and stability margins. The purpose of life-extending-control (LEC) is to study the relationship between control action and engine component life usage, and to design an intelligent control algorithm to provide proper trade-offs between performance and engine life usage. The benefit of this approach is that it is expected to maintain safety while minimizing the overall operating costs. With the advances of computer technology, engine operation models, and damage physics, it is necessary to reevaluate the control strategy for overall operating cost consideration. This paper uses the thermo-mechanical fatigue (TMF) of a critical component to demonstrate how an intelligent engine control algorithm can drastically reduce the engine life usage with minimum sacrifice in performance. A Monte Carlo simulation is also performed to evaluate the likely engine damage accumulation under various operating conditions. The simulation results show that an optimized acceleration schedule can provide a significant life saving in selected engine components.
\end{abstract}

\section{Nomenclature}

$D \quad$ True Ductility

$\Delta \varepsilon_{t} \quad$ Total Strain Range

$\Delta T_{\max }$ Maximum Temperature Difference between the airfoil and the endwall

E Modulus of Elasticity

ECU Engine Control Unit

ITT Inter Turbine Temperature

LCF Low Cycle Fatigue

$N_{c} \quad$ Safe Life Cycles

$N_{f} \quad$ Cycles-to-failure (Design)

$N_{e q} \quad$ Equivalent Cycle

$\mathrm{NH}$ High Pressure Turbine Speed 
NL Low Pressure Turbine Speed

PLA Power Lever Angle

$\sigma_{U T S} \quad$ Ultimate Tensile Strength

T3 Compressor Discharge Temperature

T4 Turbine Inlet Temperature

$T_{\text {metal }}$ Metal Temperature of Airfoil

TMF Thermo-Mechanical Fatigue

\section{Introduction}

Current aircraft engine controllers are designed and operated to provide desired performance and stability margins. Except for the hard limits for extreme conditions, engine controllers do not usually take the engine component life into consideration during the controller design and operation. The end result is that aircraft engines are regularly operated under unnecessarily harsh conditions to strive for optimum performance. This research is to study the relationship between control action and engine component life usage, and to design an intelligent control algorithm to provide proper trade-offs between performance and engine life usage. The benefit of this approach is that it is expected to maintain operating safety while minimizing the overall operating costs. Tradeoffs between performance and structural durability may be achieved for different levels of mission requirements and at different stages of engine life.

The concept of life-extending-control (LEC) was originally proposed and demonstrated in simulation for rocket engines in the early 90s [1-5]. The lifeextending-control research for aircraft engines was initiated by NASA in the late 90 s $[6,7]$. The objective of the LEC for aeropropulsion engines is to maintain the desired performance and operability while reducing component damage. To meet this challenge, the approach taken is to adjust the standard engine control logic under current constraints. This paper presents the potential benefit of an intelligent LEC logic as it applies to commercial gas turbine engines. This study demonstrates how an intelligent engine control algorithm can drastically reduce the thermo-mechanical fatigue TMF damage of a commercial aircraft engine's high pressure turbine's first stage cooled stator.

This paper will first describe the model for the TMF damage to aircraft engine components. An overview of the Matlab ${ }^{\mathrm{TM}}$ simulation that contains the engine control, engine, component thermal model, and component life model is presented next. The optimization procedure of the controller is then described. Monte-Carlo simulations of the life extending control algorithm under different operating conditions throughout the 5,000 cycle design life are described next. This is followed by a discussion of the new life extending control algorithm and its limitations. 


\section{TMF Damage}

A gas turbine engine consists of various components. These components are subject to different types of thermal mechanical damage. Specifically, hotsection components experience an accelerated rate of damage. We are mostly interested in a type of damage for hot-section components called thermomechanical fatigue (TMF). TMF damage on hot section components is one of the major factors in the engine being removed for maintenance. These components are usually called life limiting parts (LLP). Since this damage is continuously accumulated while the engine is in service, the capability of tracking this damage and controlling the engine to avoid excessive damage (lifeextending control) is desired.

TMF damage is the accumulation of strain at the microstructural level of the material. Once a sufficient amount of strain has been accumulated, the material cannot sustain input of additional strain energy, and microcracks may form. The time taken to arrive at this condition is a function of the applied strain, material properties, operating temperature, and number of repetitions. These microcracks then act as initiation sites for crack propagation to begin. In an aircraft engine, the maximum strain damage usually occurs during the take-off condition where maximum power is applied $[8,9,10,11]$. This damage is a type of low-cyclefatigue (LCF), and the engine cycle-to-failure life $N_{f}$ is usually represented by a number of standard operating cycles that will produce enough accumulated damage to cause an engine failure (i.e. crack initiation in many cases). The operating cycle limit is usually selected as a fraction of the calculated number of cycles-to-failure $N_{f}$ according to the criticality of the component. In this study, the TMF model of a cooled turbine stator (of a commercial engine) is used to illustrate the relationship of TMF damage and the variation of operating parameters.

The relationship between the cycles-to-failure $N_{f}$ and the strain range $\Delta \varepsilon_{t}$ is usually described by the following equation known as the "Method of Universal Slopes (MUS)" curves:

$$
\Delta \varepsilon_{\mathrm{t}}=3.5\left(\sigma_{\mathrm{UTS}} / \mathrm{E}\right)\left(\mathrm{N}_{\mathrm{f}}\right)^{-0.12}+\mathrm{D}^{0.6}\left(\mathrm{~N}_{\mathrm{f}}\right)^{-0.6}
$$

where $\Delta \varepsilon_{t}$ : Total Strain Range

$\sigma_{U T S}:$ Ultimate Tensile Strength

$E$ : $\quad$ Modulus of Elasticity

$D$ : $\quad$ True Ductility

$N_{f}: \quad$ Cycle-to-failure (Crack Initiation)

Note that $\sigma_{U T S}, E$, and $D$ are all functions of operating temperature. Equation (1) is usually plotted as a family of isothermal curves for different metal operating 
temperature. The total strain range $\Delta \varepsilon_{t}$ is obtained by the engine operating parameters which are usually determined by the maximum temperature gradient across the component. $N_{f}$ is then determined by the isothermal curve according to the corresponding operating temperatures. In selecting the "safe life" of a component, the " $10 \%$ Rule" is a commonly used practice $[11,12]$. It simply sets the limit of operation at one tenth of $N_{f}$.

Figure 1 shows a total-strain-range to cycles-to-failure curve and a safe life curve set by the " $10 \%$ Rule." In this case, $N_{f}$ is calculated as 50,000 standard takeoff/landing missions, and safe life limit $N_{c}$ is selected as 5,000 .

While $N_{f}$ depends on the material property as well as the operating conditions, it is more convenient to set $N_{f}$ as a constant for a standardized condition and adjust the equivalent cycle count $N_{e q}$ for actual operating usage.

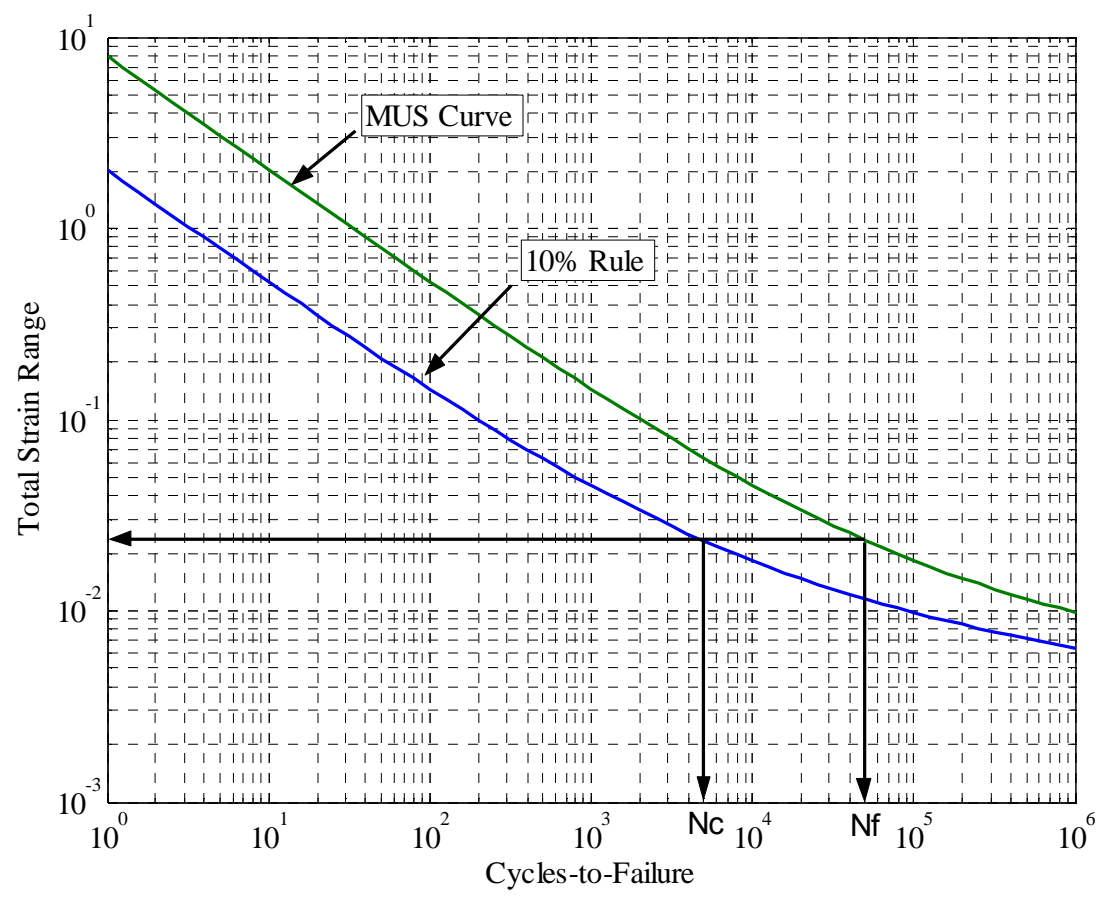

Figure 1.-Cycle-to-Failure Curve and 10\% Rule.

\section{Engine Simulation}

In order to study the engine operation during the engine service cycle, a closedloop simulation of an in-service commercial turbine engine was built using the Matlab/Simulink ${ }^{\text {TM }}$ simulation tool. The engine simulation uses a piece-wise linear model of the engine and the embedded $C$ code of the digital engine controller unit (ECU). A damage model for the turbine first stage cooled stator is 
also included in the simulation. The block diagram of this simulation model is shown in figure 2.

The external inputs to the ECU are altitude, Mach number, $\Delta T$ (Temperature bias from standard ambient condition) and PLA (Power Lever Angle, a thrust request from the pilot). The ECU also uses engine sensor outputs such as P3 (High Pressure Compressor Discharge Pressure), ITT (Interstage Turbine Temperature), NH (High Pressure Turbine Speed), and NL (Low Pressure Turbine Speed) to determine the fuel flow. Although the $\mathrm{NH}$ acceleration schedule is part of the controller (ECU), it is pulled out of the controller in figure 2 to make the acceleration schedule as an input variable in this simulation study.

During the transient, the ECU takes the thrust command (PLA) from the pilot, generates a fuel command based on operating condition and measured engine parameters. This fuel command is then modified by a series of limit logics established by speed controls, acceleration and deceleration controls, pressure controls, and fuel flow constraints. The $\mathrm{NH}$ acceleration schedule plays an important role in the ground idle to take-off transient operation because the controller is usually riding on the acceleration limits during this period.

The inputs to the engine model are altitude, Mach number, ambient temperature, and fuel flow. The engine model represents a commercial in-service engine used by regional aircraft.

The damage models of the hot section use engine model outputs to calculate the damage accumulated during the engine operation. The TMF damage of the high pressure first stage stator (cooled) is used in this study to demonstrate the concept of the life extending control.

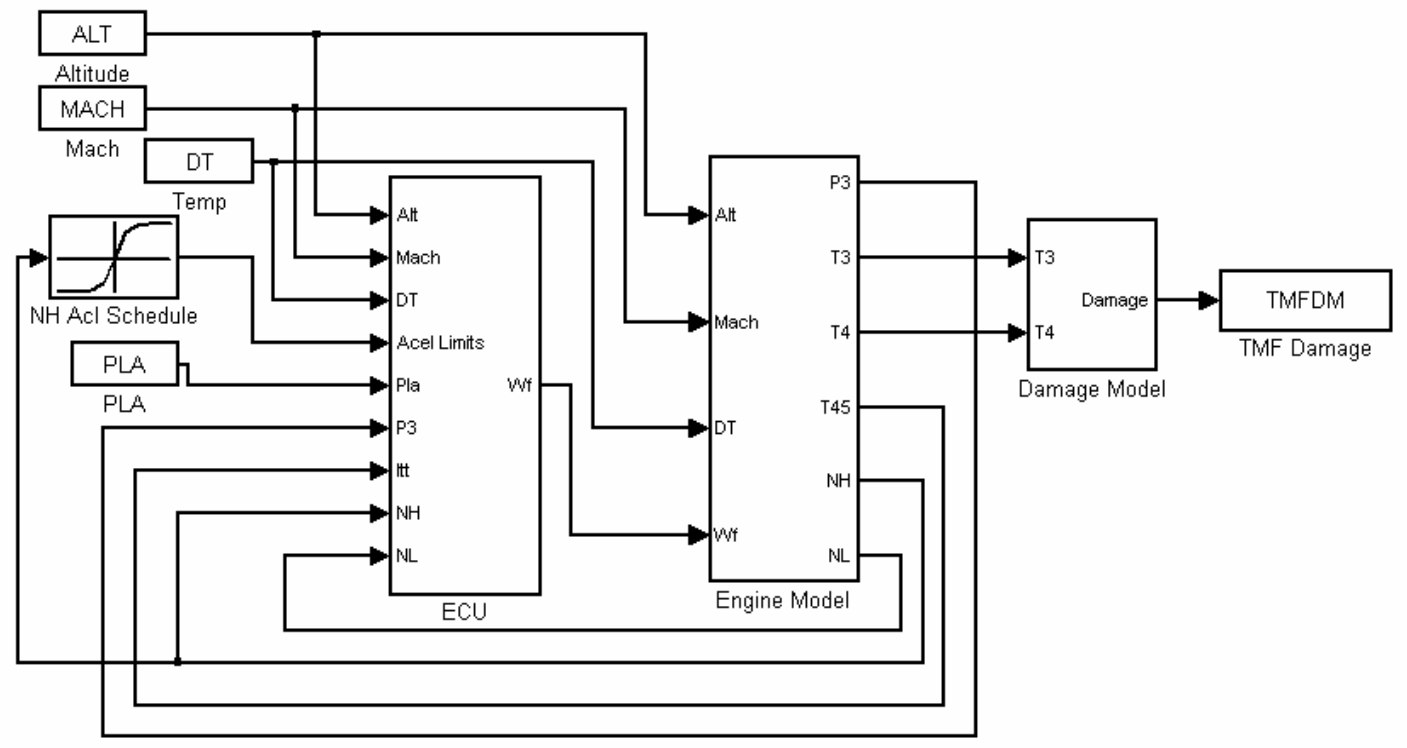

Figure 2.-Closed-loop Engine Simulation and Damage Model. 


\section{TMF Damage Reduction}

A study of the TMF damage model indicates that, during each flight cycle, the maximum temperature difference between the stator airfoil and endwall, and the maximum metal temperature of the airfoil determine the damage to the cooled stator. This maximum temperature difference occurs mostly during take-off when the engine is accelerated from ground idle to maximum power. Therefore, the TMF damage reduction can be obtained by modifying how the engine is accelerated from ground idle to maximum power.

In the modification of the engine acceleration schedule, the goal is to reduce the TMF damage while maintaining sufficient engine acceleration. Several approaches to modify the engine control logic were investigated. These include: target speed offset, control gain increase/decrease, and acceleration schedule reduction. It was found through engine simulation that acceleration schedule reduction is the most effective.

The approach taken here to reduce TMF damage is to modify the high speed turbine $(\mathrm{NH})$ acceleration control logic of the embedded controller. The current $\mathrm{NH}$ acceleration schedule of the engine controller is illustrated as the baseline case in figure $3 a$. In figure $3 a$, the maximum acceleration rate is applied when $\mathrm{NH}$ is low. Once $\mathrm{NH}$ reaches $85 \%$ of its rated speed, the acceleration is scheduled to be reduced linearly until $\mathrm{NH}$ reaches its rated speed. The acceleration rate is further reduced after $\mathrm{NH}$ goes beyond its rated speed. This schedule is the maximum acceleration limit applied by the controller (ECU). This schedule is generated during the controller design to maximize the performance and to meet the FAA rise time requirements. However, because of the nature of the TMF damage and the extreme engine operating condition, it is found that a small change in the engine acceleration schedule can have a considerable effect on the TMF damage. 


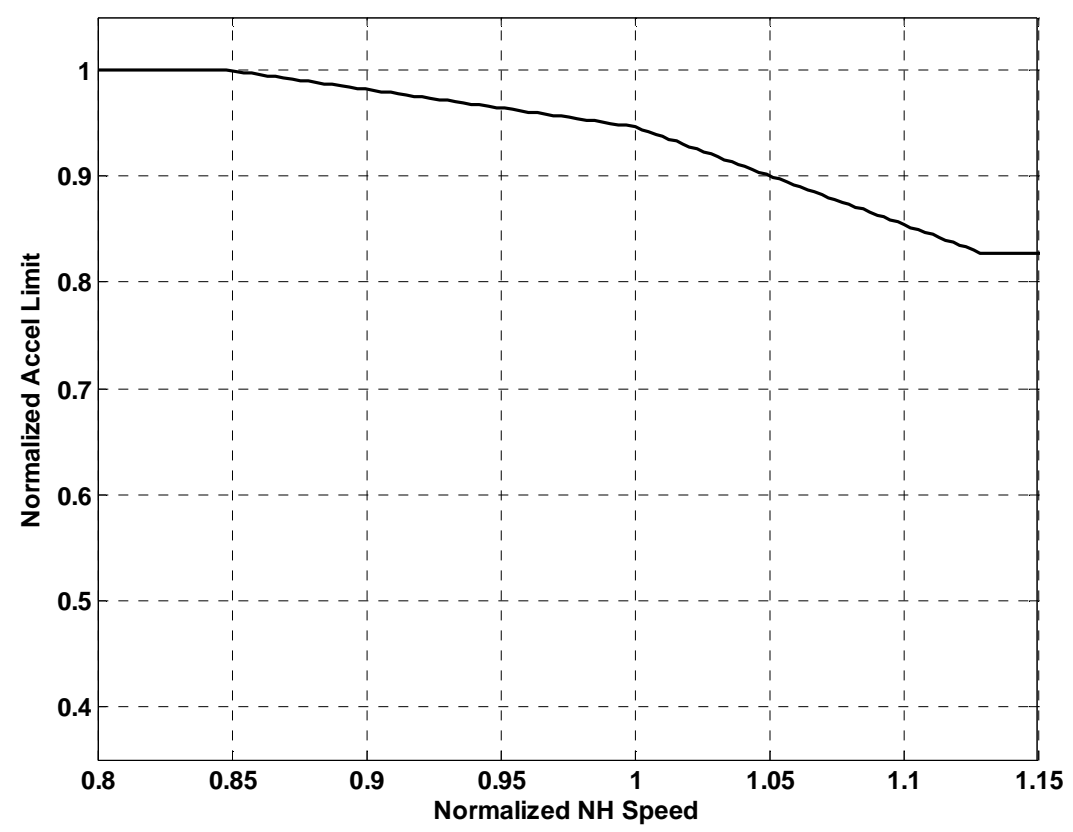

Figure 3a.-Original Acceleration Schedule (Normalized).

\section{Optimization of the Acceleration Schedule}

In a typical turbine engine control, engine acceleration follows an acceleration schedule; specifically, engine core speed is controlled to follow the acceleration schedule. As is shown in figure 2, the change of acceleration schedule will affect the actuator commands in the controller, which in turn will change the operation of the engine. This is especially important during the take-off condition because the engine is usually operated at the acceleration limit for maximum performance. In general, a slower acceleration rate can reduce the TMF damage during the take-off at the cost of slowing down the engine response time. The FAA has a strict rule on the minimum engine rise time from ground idle to full power during the take-off condition for safety reasons. A faster acceleration schedule allows the engine to reach full thrust faster but it will also put the engine through a harsher operating condition and cause it to incur more TMF damage.

In searching for an optimum acceleration schedule, the following constraints during the take-off are imposed: 1) the turbine engine is required to accelerate to $95 \%$ power in 6 seconds during a ground idle to maximum power transient; 2 ) the turbine engine is required to settle at maximum power in 8 seconds after a transition from ground idle in 8 seconds; and 3 ) the maximum acceleration limit in figure 2 is the physical limit and can not be violated. The original design of the controller has a rise time of 5.5 seconds. It is assumed a small delay up to 0.4 seconds in rise time will be acceptable. 
The goal of this optimization process is to find an acceleration schedule that will minimize the first stage stator TMF damage for a given rise time. It is obvious that a different rise time requirement will have a different optimized acceleration schedule and thus a different minimum TMF damage value. For comparison purposes, the original controller has a rise time (for engine thrust) of 5.50 seconds and designed TMF damage of 1/5000 of its usable design life (or 5,000 usable mission cycles).

It shall also be pointed out that although the ECU (controller) controls the acceleration of $\mathrm{NH}$ (high pressure turbine speed) the rise time of $\mathrm{NH}$ is different then the rise time of thrust (FAA requirement). Because of the nonlinear nature of the engine operation, the complicated TMF life model, the time lag between $\mathrm{NH}$ and thrust output, and the limits applied to rise time during acceleration, it is difficult to perform an optimization using existing optimization software packages.

To simplify the optimization, it is assumed the $\mathrm{NH}$ acceleration is monotonically decreasing as $\mathrm{NH}$ speed increases as the original design suggested. It is also assumed that the $\mathrm{NH}$ schedule can be described by two polynomial curves, representing initial acceleration reduction phase and final acceleration reduction phase, respectively. This is a generalization of the initial design of two linear segments for the acceleration reduction schedule. A steepest descent search based on the parameter perturbations of the acceleration schedule was performed. The best combinations of points which minimize the TMF damage while meeting all the required constraints are selected.

Figure $3 \mathrm{~b}$ shows the comparison of the three optimum schedules for rise times of 5.5, 5.7, and 5.9 seconds, respectively, and the original schedule. These acceleration schedules provide the best results in minimizing the TMF damage for specified rise time requirements. These schedules suggest that the controller shall continue the maximum acceleration of $\mathrm{NH}$ beyond the designed $85 \% \mathrm{NH}$ speed, and take a sharper cut in the acceleration to reduce the maximum strain at the peak temperature. This acceleration schedule strategy will keep the rise time relatively constant while reducing the maximum $\Delta T$ between airfoil and stator endwall. 


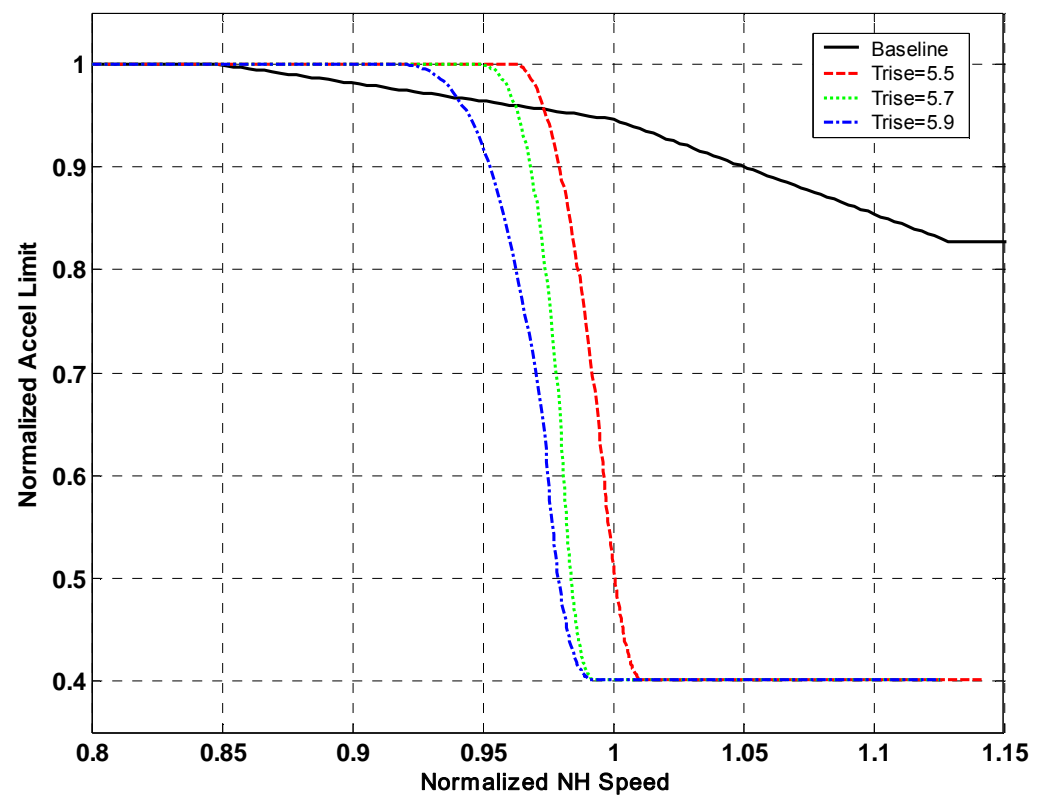

Figure 3b._Optimized Acceleration Schedule (Normalized).

Table 1 shows the simulation results of the optimized schedule. The simulation results show that the new control schedules can reduce the maximum metal temperature as well as the maximum $\Delta T$ between the stator airfoil and endwall of the cooled stator. As described above, the $\Delta T$ is a major factor of the TMF damage. Comparing to the baseline case, an optimized acceleration schedule can reduce the TMF damage of the selected component by $34 \%$ for standard flight conditions while keep the rise time unchanged. This is translated to about $52 \%$ more flights before the removal of the component from service.

Table 1 also shows that the TMF damage can be reduced even more if the engine is allowed to incur a small delay in thrust rise time. The trade-offs between rise time and TMF damage can be significant. For the optimized curves, a delay in rise time from 5.5 to 5.6 seconds can reduce the engine usage equivalent cycles from 3,300 to 2,700 . The savings in engine component life usage (TMF damage in this case) is very significant when the engine performance (rise time) can be slightly degraded. This result is important for engine controller design philosophy because it may prompt the reevaluation of engine performance requirements to account for overall operating cost. 
Table 1.-The optimized TMF damage vs. rise time.

\begin{tabular}{|c|c|c|c|c|c|}
\hline $\begin{array}{c}\text { Rise } \\
\text { Time }\end{array}$ & $\begin{array}{c}\text { Max } \mathrm{T}_{\text {Metal }} \\
\text { (difference } \\
\text { from } \\
\text { baseline) } \\
{ }^{\circ} \mathrm{F}\end{array}$ & $\begin{array}{c}\Delta T_{\max } \\
\text { (difference } \\
\text { from } \\
\text { baseline) } \\
{ }^{\circ} \mathrm{F}\end{array}$ & $\begin{array}{c}\text { Equivalent } \\
\text { Usage for } \\
5,000 \text { Flights } \\
N_{\text {eq }}\end{array}$ & $\begin{array}{c}\text { Poly. } \\
\text { Order }\end{array}$ & Note \\
\hline 5.50 & Baseline & Baseline & 5,000 & 1 & Original \\
\hline 5.50 & -16 & -30 & $3,300(66 \%)$ & 2 & Optimized \\
\hline 5.60 & -16 & -44 & $2,700(54 \%)$ & 3 & Optimized \\
\hline 5.70 & -16 & -50 & $2,450(49 \%)$ & 3 & Optimized \\
\hline 5.80 & -16 & -59 & $2,200(44 \%)$ & 3 & Optimized \\
\hline 5.90 & -16 & -65 & $2,100(42 \%)$ & 3 & Optimized \\
\hline
\end{tabular}

Figure 4 shows the thrust response curves of the selected optimized acceleration schedules during the take-off acceleration process. It only shows the area close to the rated power to illustrate the differences of rise time and overshoot. Although the thrust is not directly controlled, it is shown here because of the strict requirement of the thrust response time during the take-off. It must also be remembered that the optimized acceleration schedule in this study is for $\mathrm{NH}$ (High speed spool). In general, there is a lag between the rise of the high speed spool and thrust. It can be seen that the optimized thrust curves are kept at a slower acceleration rate when approaching the full power level. Although the overshoots are about the same in all cases, the maximum metal temperatures are all reduced in the optimized cases compared to the baseline. The slow acceleration can also help reduce the maximum temperature difference between the stator airfoil and endwall.

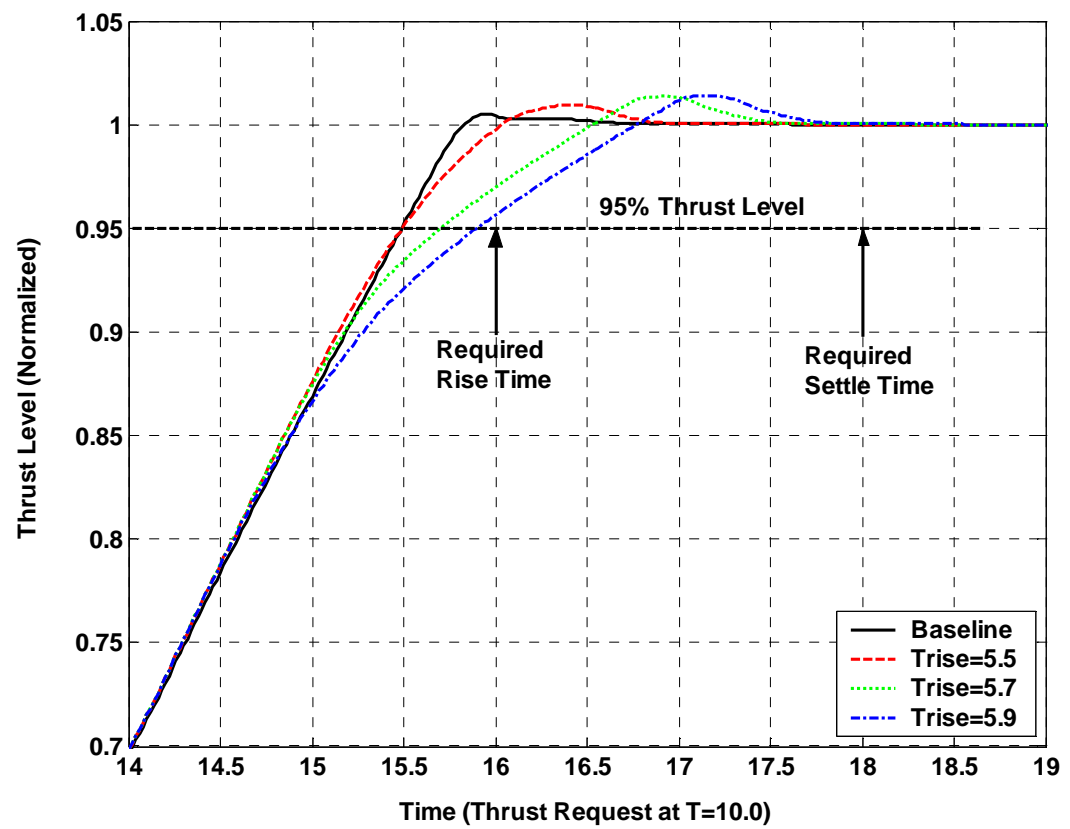

Figure 4.--Response Curves for Different Optimized Schedules. 


\section{Monte-Carlo Simulation}

Aircraft engines are typically operated at a variety of altitudes and ambient temperature conditions during their lifetime of use. In this section we will simulate the effect of these variations on the TMF damage accumulated during a typical usage of 5,000 flights. Temperature deviations are included by adding a normally distributed random value with a standard deviation of $20^{\circ} \mathrm{F}$ to the standard ambient temperature. Altitude is randomly distributed between 0 and 1,000 feet. Operating uncertainties including sensor noise and actuator errors, and possible material uncertainties, are all simulated in this study. Also, an engine may degrade over its operation life. A degraded engine will typically run at a high temperature in order to compensate for the loss of efficiency. The aging effect is simulated by adding a temperature bias to the normal operating temperature. In all cases, 5,000 take-offs are simulated under these conditions. This simulation represents typical component usage given realistic variation in ambient conditions that are likely to be encountered by the engine during its lifetime of use. A comparison of the component life usage of the original control schedule and the new control schedules is presented in Table 2.

Table 2.-The Optimized TMF damage vs. rise time.

\begin{tabular}{|c|c|c|c|c|c|c|}
\hline & Baseline & $\mathrm{T}_{\text {rise }}=5.5$ & $\mathrm{~T}_{\text {rise }}=5.6$ & $\mathrm{~T}_{\text {rise }}=5.7$ & $\mathrm{~T}_{\text {rise }}=5.8$ & $\mathrm{~T}_{\text {rise }}=5.9$ \\
\hline$N_{\text {eq, }}$ & 5,850 & 3,680 & 3,160 & 2,970 & 2,770 & 2,660 \\
Equivalent & & $(63 \%)$ & $(54 \%)$ & $(51 \%)$ & $(47 \%)$ & $(45 \%)$ \\
Life Usage & & & & & & \\
After 5,000 & & & & & & \\
Flights & & & & & & \\
\hline
\end{tabular}

The simulation results in Table 2 show that typical engine usage including simulated flight variations can cause more damage to be accumulated than originally designed for [13]. Also, the optimized schedules show similar damage reductions to the standard condition cases shown in Table 1.

Figure 5 shows the distribution of the normalized life usage of each take-off cycle from the Monte-Carlo simulations. It can be seen that the baseline condition has a very wide spread of the life usage. The optimized control scheme not only reduces the average life usage, it also reduces the usage variation so that the life prediction can be more consistent. 


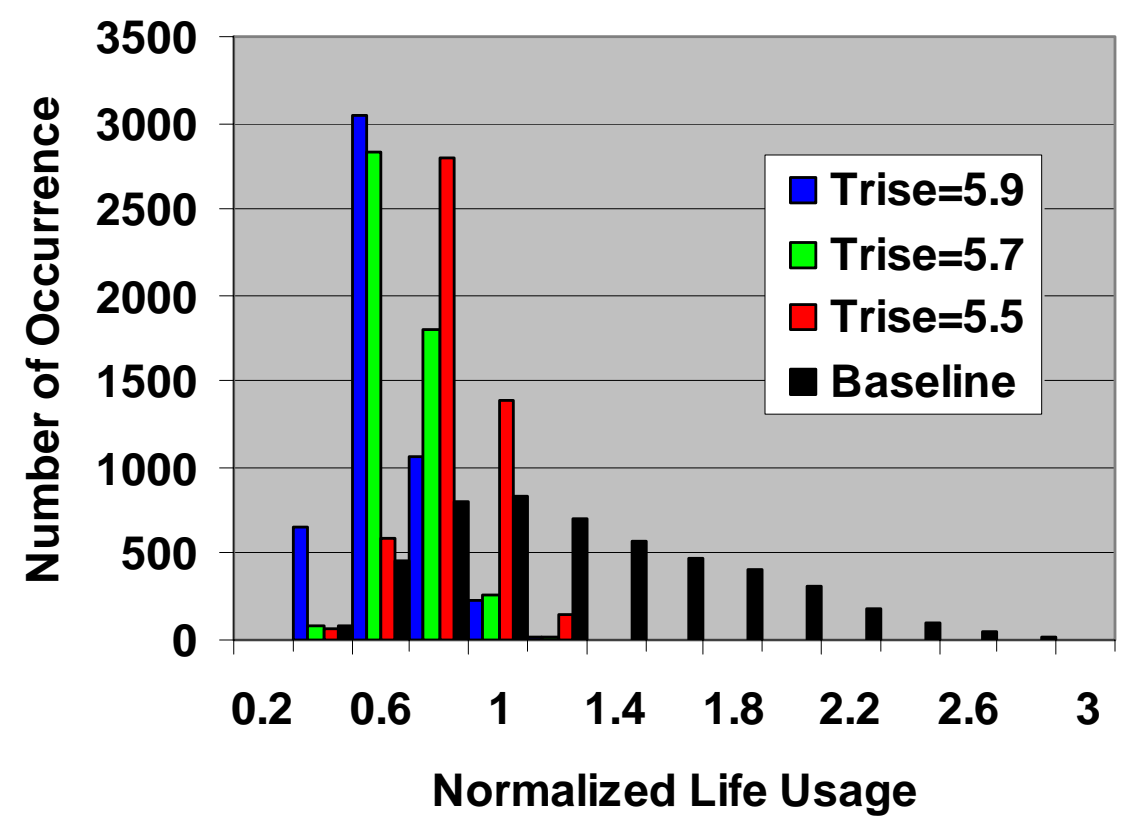

Figure 5._Equivalent Life Usage over 5,000 Flights.

\section{Discussion}

In this study, a new acceleration schedule was used to control the engine take-off procedure. The computer simulation shows that an optimized acceleration schedule with the same rise time can drastically reduce the selected TMF damage. The TMF damage can be further reduced if the rise time can be increased slightly. However, it must be understood that there are many important assumptions in this exercise, and there are many areas of research that need to be investigated before the proposed algorithm can be further validated and implemented. One of the most important research areas is the damage modeling of the life limiting parts. Although the TMF life model used in this study is the same one used by the engine company for lifing purposes during the design phase for standard conditions, it may not be totally valid to use in a wide range of dynamic conditions. Second, the engine operation model and the thermal model are also very important in calculating the TMF life usage. Because the TMF damage is very sensitive to the thermal conditions of the operation, it is necessary to develop a high fidelity dynamic thermal model to better predict the thermal conditions of a high pressure turbine. It is also important to clarify that this study uses only one failure mode (TMF damage of a cooled stator), and the controller schedule is tuned to minimize this failure mode only. It is important to examine the effect of the optimization process on other failure modes. However, it is generally accepted that lower engine operating temperatures will extend engine life. 
Finally, instead of viewing this research result as providing a solution to extend engine operating life, it is better to take this as a suggestion for new challenging research opportunities. The important research topics are: 1) given all new instrumentation and knowledge about engine operation, how do we build a better life usage model to predict engine life usage? And, 2) how do we design an engine controller that will take into consideration engine damage as well as performance to minimize the overall operating cost?

\section{Summary}

A new control scheme that modifies the acceleration schedule has been proposed as a method of control during engine take-off. A computer simulation was performed to simulate the take-off operation and life usage of various conditions. It is found that the optimized schedule can save as much as $35 \%$ of the TMF damage of the cooled stator of the high pressure turbine without sacrificing the performance. The engine life usage can be further reduced with a small increase in the rise time. The research results depend heavily on the fidelity of the engine operation model, thermal model, and life model. Research in these areas is important to the success of life extending control.

\section{References}

1. Ray, A., Dai, X., Wu, M.K., Carpino, M., Lorenzo, C., "Damage-mitigating Control of a Reusable Rocket Engine," AIAA Journal of Propulsion and Power, vol. 10, pp. 225-233, 1994.

2. Ray, A., Wu, M.K., Carpino, M., Lorenzo, C., "Damage-mitigating Control of Mechanical Systems: Part I: Concept Development and Model Formulation," AIAA Journal of Dynamic Systems, Measurement, and Control, vol. 116, pp. 437-447, 1994.

3. Ray, A., Wu, M.K., Carpino, M., Lorenzo, C., "Damage-mitigating Control of Mechanical Systems: Part II: Formulation of an Optimal Policy and Simulation," AIAA Journal of Dynamic Systems, Measurement, and Control, vol. 116, pp. 448-455, 1994.

4. Dai, X., Ray, A., "Damage-mitigating Control of a Reusable Rocket Engine: Part I Life Prediction of the Main Thrust Chamber Wall," ASME Journal of Dynamic Systems, Measurement, and Control, vol. 118, pp. 401-408, 1996.

5. Dai, X., Ray, A., "Damage-mitigating Control of a Reusable Rocket Engine: Part II-Formulation of an Optimal Policy," ASME Journal of Dynamic Systems, Measurement, and Control, vol. 118, pp. 409-415, 1996.

6. Guo, T.-H., "A Roadmap for Aircraft Engine Life Extending Control," Proceedings of the 2001 American Control Conference, June 2001, Arlington, VA.

7. Jaw, L.C., Wu, D., Guo, T.-H., McCarty, R., "Design of an Intelligent LifeExtending Control for Turbine Engines," 2001 American Control Conference, June, 2001, Arlington, VA.

8. Anderson, T.L., Fracture Mechanics, Second Ed., CRC Press, 1995. 
9. Mason, S.S., "Fatigue - A Complex Subject." Experimental Mechanics, Vol. 5, No. 7, 1965. pp. 193-226.

10.Cruse, T.A., Gallagher, J.P., editors, Fatigue Life Technology, ASME, 1977.

11. Halford, G.R., Lerch, B.A., Saltsman, J.F., "Proposed Framework for ThermoMechanical Fatigue Life Modeling of Metal Matrix Composites," NASA TP3320, July 1993.

12. Halford, G.R., Mason, S.S., "Application of a Method of Estimating HighTemperature Low-Cycle Fatigue Behavior of Materials." Trans. ASM Quarterly, American Society for Metals, Metals Park, OH, Vol. 61, No. 1, pp. 94-102, 1968.

13. Guo, T.-H., Chen, P. "Sensor Based Engine Life Calculation - A Probabilistic Perspective," Proceedings of $16^{\text {th }}$ International Symposium on Airbreathing Engines, ISOABE, Cleveland, OH, 2003. 


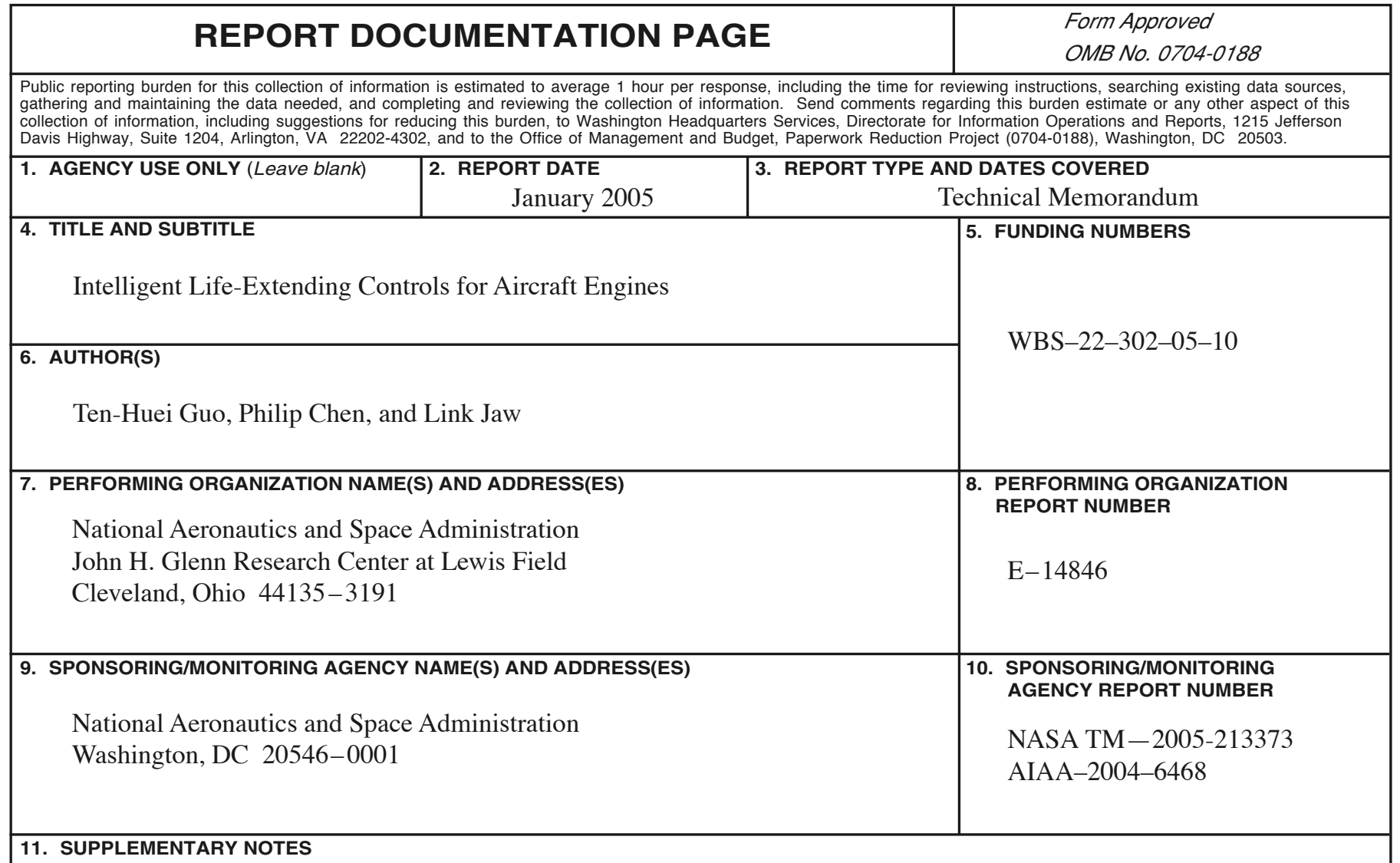

Prepared for the First Intelligent Systems Technical Conference sponsored by the American Institute of Aeronautics and Astronautics, Chicago, Illinois, September 20-22, 2004. Ten-Huei Guo, NASA Glenn Research Center; Philip Chen, University of Texas at San Antonio, San Antonio, Texas 78249-0600; Link Jaw, Scientific Monitoring, Inc., Scottsdale, Arizona 85258-3345. Responsible person, Ten-Huei Guo, organization code RIC, 216-433-3734.

\begin{tabular}{|l|l}
\hline 12a. DISTRIBUTION/AVAILABILITY STATEMENT & 12b. DISTRIBUTION CODE \\
Unclassified - Unlimited & \\
Subject Category: 05 & \\
Available electronically at http://gltrs.grc.nasa.gov & \\
This publication is available from the NASA Center for AeroSpace Information, 301-621-0390. &
\end{tabular}

\section{ABSTRACT (Maximum 200 words)}

Aircraft engine controllers are designed and operated to provide desired performance and stability margins. The purpose of life-extending-control (LEC) is to study the relationship between control action and engine component life usage, and to design an intelligent control algorithm to provide proper trade-offs between performance and engine life usage. The benefit of this approach is that it is expected to maintain safety while minimizing the overall operating costs. With the advances of computer technology, engine operation models, and damage physics, it is necessary to reevaluate the control strategy fro overall operating cost consideration. This paper uses the thermo-mechanical fatigue (TMF) of a critical component to demonstrate how an intelligent engine control algorithm can drastically reduce the engine life usage with minimum sacrifice in performance. A Monte Carlo simulation is also performed to evaluate the likely engine damage accumulation under various operating conditions. The simulation results show that an optimized acceleration schedule can provide a significant life saving in selected engine components.

14. SUBJECT TERMS

Fatigue life; Fatigue (materials); Thermal fatigue; Engine control; Adaptive control

\begin{tabular}{|c|c|c|c|}
\hline $\begin{array}{c}\text { 17. SECURITY CLASSIFICATION } \\
\text { OF REPORT } \\
\text { Unclassified }\end{array}$ & $\begin{array}{c}\text { 18. SECURITY CLASSIFICATION } \\
\text { OF THIS PAGE } \\
\text { Unclassified }\end{array}$ & $\begin{array}{c}\text { 19. SECURITY CLASSIFICATION } \\
\text { OF ABSTRACT } \\
\text { Unclassified }\end{array}$ \\
\hline
\end{tabular}



